\title{
Ameliorative Effect of Ethanolic Extract of Cucumis Sativus (Cucumber) Pulp on Alloxan Induced Kidney Toxicity in Male Adult Wistar Rats
}

\author{
Uzozie Chikere Ofoego $^{1^{*}} \quad$ Elizabeth Obioma Nweke ${ }^{2} \quad$ Ogbonna Mishael Nzube $^{1}$ \\ 1. Department of Anatomy, Faculty of Basic Medical Sciences, Nnamdi Azikiwe University, Nnewi Campus, \\ Anambra State, Nigeria \\ 2. Department of Anatomy, Faculty of Basic Medical Sciences, Chukwuemeka Odumegwu Ojukwu University, \\ Anambra State, Nigeria
}

\begin{abstract}
Nephropathy is a common complication of diabetes, managed with both orthodox and herbal remedies. Cucumis sativus is a creeping plant belonging to the Cucurbitaceae family. Its edible fruits possess diverse pharmacological activities. This study investigated the effect of ethanolic extract of cucumis sativus pulp (EECSP) on alloxan induced renotoxicity in adult male Wistar rats. Thirty adult male Wistar rats weighing between 170-190g were purchased and acclimatized for 2 weeks and afterwards grouped into 6 groups (A-F) of 5 rats each. Group A (Control) received distilled water and rat feed ad libitum. Diabetes was induced in Groups B, C, D, and E with consequent renotoxicity using a single intraperitoneal injection of $150 \mathrm{mg} / \mathrm{kg}$ of Alloxan after an overnight fast. Group C, D and E were afterwards treated with 100,250 and $500 \mathrm{mg} / \mathrm{kg}$ of ethanolic extract of cucumis sativus pulp respectively. Group F received $500 \mathrm{mg} / \mathrm{kg}$ of EECSP. Extract administration was oral and once daily for 28days. At the end of the experiment, blood samples were collected via ocular puncture and sera separated for kidney function test. The animals were sacrificed and their kidneys collected, and prepared for light microscopy. Results showed that treatment with EECSP caused a dose dependent restoration of kidney architecture and renal functions when compared with untreated alloxan group that showed severe distortions in renal architecture and higher than normal serum urea and creatinine levels. Ethanolic extract of cucumis sativus pulp thus caused a dose dependent ameliorative effect on alloxan induced diabetic nephropathy in adult male Wistar rats.
\end{abstract}

Keywords: Nephropathy, diabetes, Cucumis sativus, alloxan

DOI: $10.7176 / \mathrm{JNSR} / 9-4-02$

\section{Introduction}

The kidney is a paired bean shaped organ located retroperitoneally, on the posterior abdominal wall, that performs vital functions in the body such as maintenance of homeostasis and blood pressure; excretion of waste products (urea, uric acid, and creatinine); and secretion of hormones (renin, and erythropoietin) (Guyton and Hall, 2006). Although protected like other organs, its position as the sieve of the body makes it exposed to not only toxins but to disease causing organisms. The kidney can be injured and consequently damaged by repeated or prolonged exposure to a lot of substances which includes, antibiotics, analgesics, COX-2 inhibitors, heartburn drugs of the proton pump inhibitor class, antiviral drugs, hypertensive drugs, rheumatoid arthritis drugs, lithium, alcohol, lithium, and chemotherapy drugs (Khalili et al., 2013; Rubina, 2017), as well as organic compound such as Alloxan (Evan et al., 1984; Yui et al., 2017).

Alloxan $(2,4,5,6$ tetraoxipyrimidine $)$ is an organic compound with the formula $\mathrm{OC}(\mathrm{N}(\mathrm{H}) \mathrm{CO})_{2} \mathrm{CO}$, a derivative of pyrimidine (Dunn et al., 1943). It is used in the production of the purple dye murexide by heating it in ammonia gas to $100^{\circ} \mathrm{C}$ (Walter, 1905). Experimentally, alloxan is often used to catalyze the formation of reactive oxygen species (ROS), more specifically, the superoxide free radical (Lenzen, 2008). Alloxan undergoes redox cycling in vivo and is reduced by electron donor such as reduced glutathione (GSH), cysteine, ascorbate and protein-bound sulfhydryl (-SH) groups (Lenzen and Munday, 1991; Zhang et al., 1992). Alloxan reacts with two -SH groups in the sugar binding site of glucokinase resulting in the formation of the disulfide bond and inactivation of the enzyme (Munday, 1988; Das et al., 2012). As a result of alloxan reduction, dialuric acid is formed which is then re-oxidized back to alloxan establishing a redox cycle for the generation of reactive oxygen species (ROS) such as superoxide radicals (Munday, 1988; Das et al., 2012).

Despite its well documented action on the pancreatic islet cells, leading to the development of symptoms typical of type 1 diabetes (Ankur and Shahjad, 2012), alloxan has been shown to be nephrotoxic, causing marked interstitial damage in healthy kidneys (Evan et al., 1984). Reports have also shown that alloxan treatment induces histological features of renal damage (inflammation and fibrosis), and has been associated with deterioration of the renal functions (elevated blood urea nitrogen and creatinine levels), hyperglycemia, and oxidative stress (increased malondialdehyde and decreased glutathione levels) (Mohamed et al., 2010). Alterations of TGF- $\beta$, p53, and extracellular matrix metalloprotenaises have also been documented to contribute to the pathogenesis of Alloxan-induced renal damage (Mohamed et al., 2010). 
Treatment of diabetes induced nephrotoxicity has over the years been achieved not only via generic drugs but also by plant/herbal concoctions. These concoctions are derived from plants rich in phytochemicals that possess vital cell, and tissue soothing properties. Such plants and herbs are not only cheap, but readily accessible. One of such plants is Cucumis sativus (Cucumber).

Cucumis sativus (Cucumber) is a widely distributed plant. It belongs to the Cucurbitaceae family, a creeping vine that roots in the ground and grows up trellises or other supporting frames, wrapping around supports with thin, spiraling tendrils (Huang et al., 2009; Trease et al., 2002). C. sativus bears edible fruit that possess diverse pharmacological activities such as antibacterial, antifungal, antidiabetic, cytotoxic, antacid, carminative, hepatoprotective, and wound healing activities, providing a significant role in the prevention and treatment of diseases (Jony et al., 2013). This is as a result of its nutritional (Vitamin B1, ascorbic acid, proteolytic enzyme, rutin, oxidase, succinic and maleic dehydrogenases) and phytochemical constituents (steroids, flavonoids, and tanins) (Kumar et al., 2010).

Limited literature exists on the effects of Cucumis sativus (Cucumber) fruit on alloxan induced diabetic kidney toxicity thus the need to carry out this research to investigated the effect of ethanolic extract of cucumis sativus pulp (EECSP) on alloxan induced diabetic renotoxicity in adult male Wistar rats.

\section{Materials and Method}

2.1 Procurement of Alloxan and Induction of Experimental Diabetes

Alloxan in the form of Alloxan Monohydrate (Sigma-Aldrich, St. Louis, MO, USA) was purchased from CyleonC Pharmacy at Nnewi, Anambra State, Nigeria. Alloxan (2, 4, 5, 6-tetraoxypyrimidine; 2, 4, 5, 6-pyrimidinetetrone) is a pyrimidine derivative, and a toxic glucose analogue that selectively destroys insulin-producing beta cells of the pancreas of experimental animal (Onyeka et al., 2013). This causes symptoms similar to type 1 diabetes in humans with consequent renotoxicity. $150 \mathrm{mg}$ of $0.5 \mathrm{grams}$ of alloxan monohydrate (Sigma chemicals, USA) was dissolved in $5 \mathrm{ml}$ of normal saline to form a stock solution, and $150 \mathrm{mg} / \mathrm{kg}$ was withdrawn and injected intraperitoneally to the experimental animals were applicable after 48 hour fast (allowed access to only water) to cause the development of diabetes. Diabetes was confirmed in alloxan-treated rats with a fasting blood sugar concentration $126 \mathrm{mg} / \mathrm{dl}$.

\subsection{Procurement of and Preparation of Cucumis Sativus (Cucumber) Fruit Extract.}

Cucumis Sativus fruits were purchased from the Nkwo market in Nnewi. They were afterwards washed in running tap water to remove dirt, and subsequently cut into pieces. These cut pieces were then shed dried and milled into coarse powder using Local grinder. $50 \mathrm{~g}$ of the cucumis sativus pulp powder was macerated in $95 \%$ ethanol for 48hours, which was then filtered using porcelain cloth and further filtered using Whatman No 1 filter paper. The filtrate was concentrated using a rotatory evaporator and was further dried using a laboratory oven at $50^{\circ} \mathrm{C}$ into a semi solid gel-like form. Part of the extract was used for phytochemical analysis while the remainder was preserved in a refrigerator at $-4^{0} \mathrm{C}$ for further usage.

\subsection{Phytochemical Screening}

Phytochemical screening was carried out using a small portion of the ethanolic extract of Cucumis sativus pulp to determine the presence of tannins, flavonoids, alkaloids, saponins and steroids using modified methods of Harborne, (1998), Tiwari et al., (2011), and Ebirien-Agana et al., (2016).

1. Dragendroff's test for Alkaloids: Dry powder extracts of Cucumis sativus pulp were dissolved in 5 milliliters of $1 \%$ hydrochloric acid on steam bath with the addition of drops of Dragendroff reagent. Presence of alkaloid was confirmed with the existence of turbidity or yellow precipitation.

2. Steroid test: Dry powder extracts of Cucumis sativus pulp were dissolved in 3 milliliters of chloroform and layered with concentrated sulfuric acid. The presence of reddish brown colour at the boundary between the reagents indicates the presence of steroid.

3. Froth test for Saponin: Dry powder extracts of Cucumis sativus pulp were dissolved in 2 milliliters of distilled water and strongly shaken for some minutes. The presence of stable foam indicates the existence of saponin.

4. Shinoda test for Flavonoid: Dry powder extracts of Cucumis sativus pulp were mixed with a small amount of magnesium ribbon and then added with drops of concentrated hydrochloric acid. The presence of pink colour indicates the existence of flavonoids.

5. Ferric (III) chloride test for Tannin: Dry powder extracts of Cucumis sativus pulp were mixed with drops of ferric (III) chloride solution. A colour change from bluish-green to black indicates the presence of tannins. 
Best Animal farms, Okofia, Nnewi, and housed in the animal house, Faculty of Basic Medical Sciences, Nnewi Campus, Nnamdi Azikiwe University, Anambra State. Animals were kept in standard plastic rat cages at a room temperature of $27 \pm 2{ }^{\circ} \mathrm{C}$, and exposed to atleast a period of 12 hours light and dark cycles. These animals were fed with rat chow (Growers Vital top feed, Jos, Nigeria) and water ad libitum for a period of two weeks prior to the onset of substrate administration. This procedure was to allow for proper acclimatization.

\subsection{Experimental Design and Protocol}

After acclimatization, these adult male Albino wistar rats were grouped into 6 groups (A-F) of 5 rats each. The administration lasted for duration of 28 days. Group A served as Control group, and received only distilled water and rat chow ad libitum throughout the duration of the experiment. Diabetes and consequent renotoxicity was induced in Groups B, C, D, and E using a single intraperitoneal injection of $150 \mathrm{mg} / \mathrm{kg}$ of Alloxan after an overnight fast. Group C, D and E were afterwards treated with 100, 250 and $500 \mathrm{mg} / \mathrm{kg}$ of ethanolic extract of cucumis sativus pulp respectively 48 hours after confirmation of diabetes. While Group F received $500 \mathrm{mg} / \mathrm{kg}$ of ethanolic extract of Cucumis Sativus. All extract were orally administered and lasted for duration of 28 days.

\subsection{Termination of Experiment, Serum Blood collection, and Organ collection}

At the end of the experiment which lasted for 30 days, the experimental animals were carefully injected with ketamine hydrochloride 24 hours after the last administration of extract so as to anaesthetize the animals. Blood samples were collected from the rats before sacrificing via ocular puncture for Kidney Function Test. These blood samples were put in plain sterilized glass tubes devoid of anticoagulant. The samples were centrifuged with a laboratory ultracentrifuge machine (New life model) and serum collected and stored in the refrigerator. Afterwards, the animals were sacrificed via cervical dislocation, dissected through the anterior abdominal region and their kidneys harvested, washed in normal saline, weighed and then transferred into specimen bottles containing freshly prepared $10 \%$ formal saline for preservation prior to histological processing. The remains of the experimental animals were properly disposed.

\subsection{Kidney Function Test}

Estimation of creatinine was carried out according to the method described by Owen et al., (1954), while estimation of urea was carried out using the method described by Marsh et al., (1965).

\subsection{Tissue Processing and Microscopy}

The harvested kidneys were fixed in $10 \%$ formal saline in specimen bottles with light fitting lids for three days to prevent autolysis; improve their staining qualities and aid optical differentiation of cell and their components. Afterwards, the fixed kidney tissues were dehydrated to remove water using ascending grades of alcohol ranging from 50\% to absolute Alcohol for 30 minutes each. Thereafter, the dehydrated tissues were cleared by removing the alcohol via immersion through three changes of xylene for 30 minutes each. These cleared tissues were then impregnated and infiltrated to remove the xylene by passing it through three changes of molten paraffin wax in a hot oven temperature of $60^{\circ} \mathrm{C}$ for 30 minutes. The infiltrated tissues were embedded in molten paraffin wax using an embedding mould and allowed to cool and solidify. The paraffin blocks obtained afterwards were trimmed so as to expose the surface of the tissue by adjusting the microtome knife to $15 \mu \mathrm{m}$. Thereafter, and sections were cut with rotary microtome and the ribbons placed on $20 \%$ alcohol, and picked on a large slide $(5 \mathrm{~cm} \mathrm{X} 7.5 \mathrm{~cm}$ slide) to remove minor folds and creases from sections. These ribbons were placed on a water bath preheated to about $45^{\circ} \mathrm{C}$ in order to float out the tissues. The tissues were then collected with clean slides, allowed to dry, and well labelled with the aid of a diamond pencil. These slides were afterwards dried on a hot plate at $5^{\circ} \mathrm{C}$ for the tissue to adhere to the slide. The tissues were dewaxed in xylene for 10 minutes and then rinsed in descending order of alcohol ranging from absolute $95 \%, 90 \%, 70 \%$ and $50 \%$ for two seconds each. The tissues were then washed in two changes of water and differentiated in 1\% acid alcohol. Afterwards, the tissues were stained using Hematoxylin and washed in tap water until the tissues colour changed to blue. The tissues were counterstained in Eosin for 5 minutes and cleared in xylene prior to mounting in DPX, and dried for photomicrography and histopathological interpretation.

\subsection{Statistical Analysis}

Data obtained from this study were analyzed using Statistical Package for Social Sciences (SPSS Version 23). The results were expressed as mean \pm Standard Error of Mean (S.E.M.). Data for Kidney Function Test (Urea \&Creatinine) was analyzed using One-way ANOVA, followed by Post hoc LSD. While body weights were analyzed using Student dependent T-test. Values were considered significant at $\mathrm{P}<0.05$. 


\section{Result}

3.1 Physical and Behavioural Observations

At the beginning of the experiment, all animals were apparently healthy and agile. During the two weeks of acclimatization, their stool was dark brown and they adapted well to their environment. However, during the first week of alloxan injection, most of the rats showed signs of weakness, reduction in food and water intake and polyuria. In the group that received alloxan and were left untreated, feeding habits improved slightly, although they got weaker as the experiment progressed. In the groups that received alloxan and were later treated with graded doses of ethanolic extract of Cucumis Sativus, feeding habits and urine outputs returned to normal as the experiment progressed. In group 5 (that received only $500 \mathrm{mg} / \mathrm{kg}$ of the ethanolic leaf extract of Cucumis Sativus), they were apparently healthy and agile throughout the duration of the experiment.

3.2 Effects on Body weight

Table 1: Effect of ethanolic extract of cucumber on body weight following Alloxan induced kidney damage

\begin{tabular}{|c|c|c|c|c|c|c|}
\hline GROUP & $\begin{array}{c}\text { INITIAL } \\
\text { BODY } \\
\text { WEIGHT }(\mathrm{g})\end{array}$ & $\begin{array}{c}\text { FINAL } \\
\text { BODY } \\
\text { WEIGHT }(\mathrm{g})\end{array}$ & $\begin{array}{c}\text { WEIGHT } \\
\text { DIFFERENCE }(\mathrm{g})\end{array}$ & $\begin{array}{c}\text { MEAN } \pm \text { SEM OF } \\
\text { WEIGHT } \\
\text { DIFFERENCE }\end{array}$ & $\begin{array}{c}\mathrm{t}- \\
\text { value }\end{array}$ & $\begin{array}{c}\mathrm{p}- \\
\text { value }\end{array}$ \\
\hline A & 120 & 160 & 40 & \multirow{4}{*}{$44.75 \pm 1.84$} & \multirow{4}{*}{15.146} & \multirow{4}{*}{$<0.001$} \\
\hline & 120 & 165 & 45 & & & \\
\hline & 125 & 170 & 45 & & & \\
\hline & 123 & 172 & 49 & & & \\
\hline B & 180 & 140 & -40 & \multirow{4}{*}{$-36.50 \pm 2.36$} & \multirow{4}{*}{13.837} & \multirow{4}{*}{$<0.001$} \\
\hline & 185 & 145 & -40 & & & \\
\hline & 178 & 142 & -36 & & & \\
\hline & 180 & 150 & -30 & & & \\
\hline $\mathrm{C}$ & 126 & 146 & 20 & \multirow{4}{*}{$13.50 \pm 2.72$} & \multirow{4}{*}{5.154} & \multirow{4}{*}{0.002} \\
\hline & 125 & 135 & 7 & & & \\
\hline & 128 & 140 & 12 & & & \\
\hline & 130 & 145 & 15 & & & \\
\hline \multirow[t]{4}{*}{$\mathrm{D}$} & 155 & 172 & 17 & \multirow{4}{*}{$15.00 \pm 2.20$} & \multirow{4}{*}{6.823} & \multirow{4}{*}{$<0.001$} \\
\hline & 150 & 170 & 20 & & & \\
\hline & 155 & 168 & 13 & & & \\
\hline & 160 & 170 & 10 & & & \\
\hline \multirow[t]{4}{*}{$\mathrm{E}$} & 160 & 175 & 15 & \multirow{4}{*}{$10.00 \pm 1.78$} & \multirow{4}{*}{6.60} & \multirow{4}{*}{0.001} \\
\hline & 162 & 170 & 8 & & & \\
\hline & 160 & 175 & 7 & & & \\
\hline & 162 & 180 & 10 & & & \\
\hline \multirow[t]{4}{*}{$\mathrm{F}$} & 123 & 170 & 47 & \multirow{4}{*}{$44.75 \pm 1.80$} & \multirow{4}{*}{19.89} & \multirow{4}{*}{$<0.001$} \\
\hline & 125 & 165 & 40 & & & \\
\hline & 120 & 168 & 48 & & & \\
\hline & 128 & 172 & 44 & & & \\
\hline
\end{tabular}

Table 2: Analysis of Variance of Mean Body Weight Difference between the Various Experimental Groups of Animals

\begin{tabular}{|c|c|c|c|}
\hline Group & $\begin{array}{l}\text { Weight Difference } \\
\text { Mean } \pm \text { SEM }\end{array}$ & F-value & Significance $(p)$ \\
\hline Group A (Control) & $44.75 \pm 1.84$ & \multirow{6}{*}{193.271} & - \\
\hline Group B & $-36.50 \pm 2.36$ & & $<0.001$ \\
\hline Group C & $13.50 \pm 2.72$ & & $<0.001$ \\
\hline Group D & $15.00 \pm 2.20$ & & $<0.001$ \\
\hline Group E & $10.00 \pm 1.78$ & & $<0.001$ \\
\hline Group F & $44.75 \pm 1.80$ & & 1.0 \\
\hline
\end{tabular}

Values were considered significant at $\mathrm{P}<0.05$. ${ }^{*} \mathrm{P}<0.05$ means significant, $\mathrm{P}>0.05$ means not significant.

Result from the tables 1 and 2 above shows that there was a significant increase in the body weight in group A when comparing the Initial weight to the Final weight. In group B, there was a significant decrease in the body weight when comparing the initial weight to the final weight. In group $C$, there was a significant increase in the body weight when comparing the Initial weight to the Final weight. In group D, there was an insignificant increase in the body weight when comparing the initial weight to the final weight. In group E, there was an insignificant increase in the body weight when comparing the initial weight to the final weight. In group F, there was a significant increase in the body weight when comparing the Initial weight to the Final weight. 
The result showed that the body weight difference increase in group $\mathrm{B}$ and $\mathrm{F}$, while a decrease in group $\mathrm{C}$ and $\mathrm{C}, \mathrm{D}$ and $\mathrm{E}$ when compared with group $\mathrm{A}$, but showed a significance in group $\mathrm{B}, \mathrm{C}$ and $\mathrm{F}$ while D and $\mathrm{E}$ was not significant.

\subsection{Effects on Sera Urea Concentration}

Table 3: Effect of ethanolic extract of cucumber on serum urea concentration following Alloxan induced kidney damage.

\begin{tabular}{|c|c|c|c|}
\hline Group & $\begin{array}{c}\text { Mean } \pm \text { SEM } \\
(\mathrm{mg} / \mathrm{dL})\end{array}$ & F-value & Significance (p) \\
\hline Group A (Control) & $9.658 \pm 0.027$ & \multirow{6}{*}{1578} & - \\
\hline Group B & $34.840 \pm 0.360$ & & $<0.001 *$ \\
\hline Group C & $25.975 \pm 0.065$ & & $<0.001 *$ \\
\hline Group D & $21.715 \pm 0.126$ & & $<0.001 *$ \\
\hline Group E & $14.925 \pm 0.407$ & & $<0.001 *$ \\
\hline Group F & $11.845 \pm 0.187$ & & $<0.001 *$ \\
\hline
\end{tabular}

$* \mathrm{P}<0.05$

Result from table 3 above showed that there was a significant increase in the serum Urea concentration in group B, C, D, E and F when compared to group A (Control). Group B that received a single intraperitoneal injection of $150 \mathrm{mg} / \mathrm{kg}$ of alloxan monohydrate only, had the highest value of serum urea levels.

3.4 Effects on Sera Creatinine concentration

Table 4: Effect of ethanolic extract of cucumber on serum creatinine concentration following Alloxan induced kidney damage.

\begin{tabular}{|c|c|c|c|}
\hline Group & $\begin{array}{c}\text { Mean } \pm \text { SEM } \\
((\mathrm{mg} / \mathrm{dL})\end{array}$ & F-value & Significance (p) \\
\hline Group A (Control) & $0.348 \pm 0.026$ & \multirow{6}{*}{97.244} & - \\
\hline Group B & $0.973 \pm 0.008$ & & $<0.001 *$ \\
\hline Group C & $0.760 \pm 0.011$ & & $<0.001 *$ \\
\hline Group D & $0.428 \pm 0.039$ & & 0.043 \\
\hline Group E & $0.398 \pm 0.023$ & & 0.189 \\
\hline Group F & $0.393 \pm 0.034$ & & 0.235 \\
\hline
\end{tabular}

$* \mathrm{P}<0.05$

Result from table 4 above showed that there was a significant increase in the serum creatinine concentration in group B, and C when compared to group A (Control). Group B that received a single intraperitoneal injection of $150 \mathrm{mg} / \mathrm{kg}$ of alloxan monohydrate only, had the highest value of serum creatinine levels.

\subsection{Histological findings}

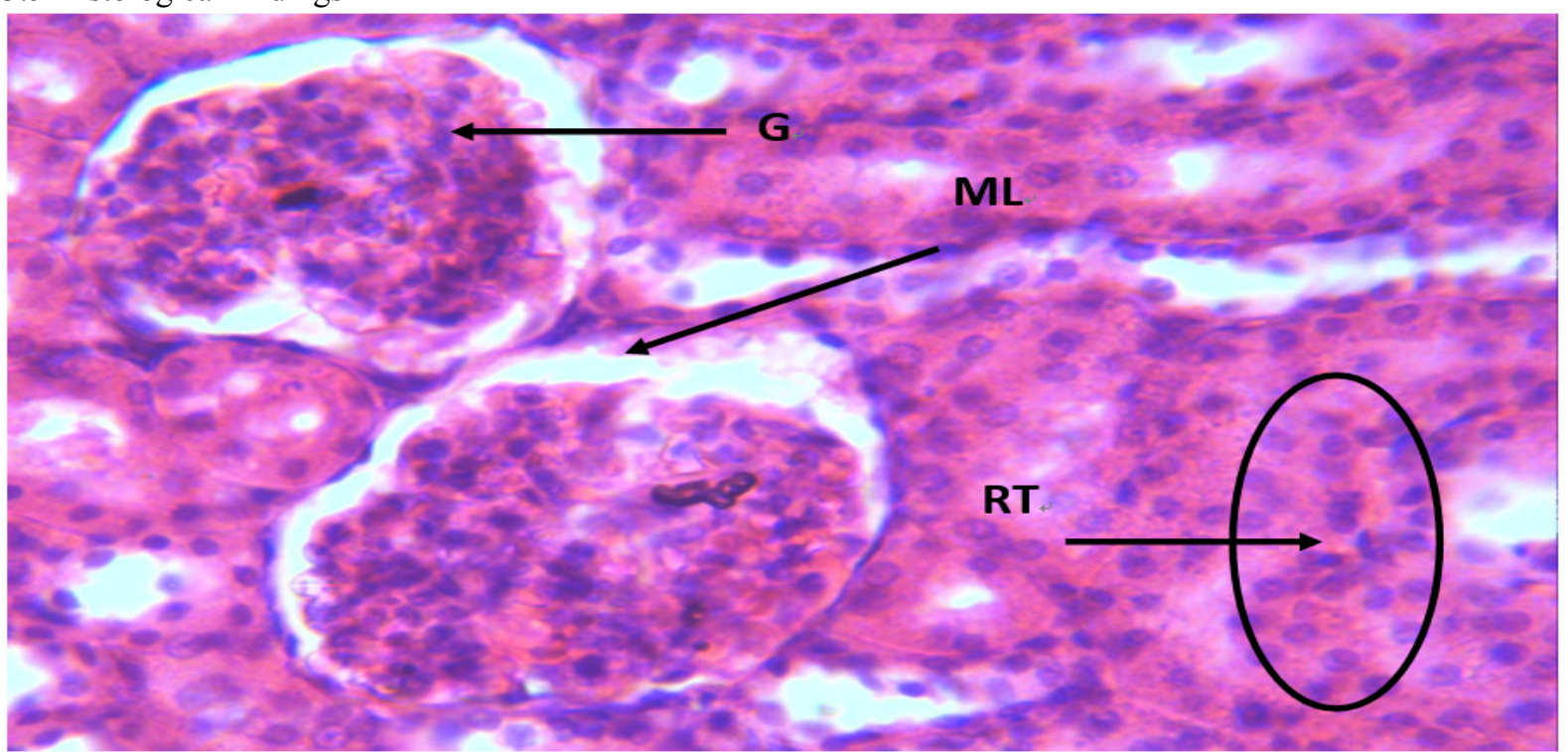

PLATE I (CONTROL) (H\&E; X 400): Administered with food and water only showing. photomicrograph section of kidney with normal renal architecture, glomeruli $(\mathrm{G})$, renal tubules (RT), and malphigian layer (ML) well represented. 


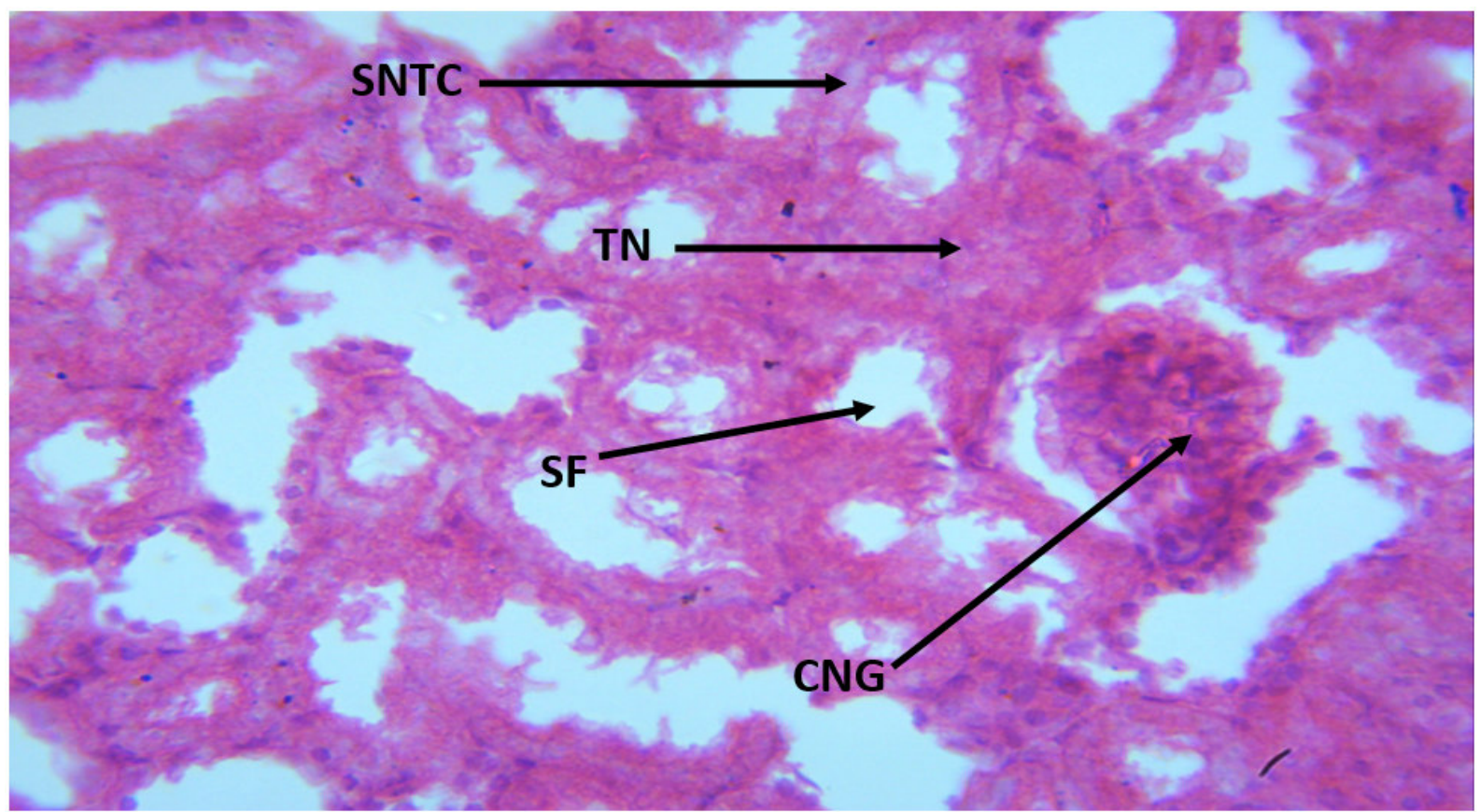

PLATE II (GROUP B) (H\&E; X 400): Administered intraperitoneally, $150 \mathrm{mg} / \mathrm{kg}$ of Alloxan only showing severe damaged on the renal tissue with severe necrosis of tubular cell (SNTC), coagulative necrosis of glomeruli $(\mathrm{CNG})$ severe fatty change (SFC) and tubular necrosis (TN).



PLATE III (GROUP C) (H\&E; X 400): Administered 150mg/kg of Alloxan first and 100mg/kg of Cucumber pulp. Photomicrograph section of kidney shows moderate restoration. However there are mild to moderate fatty changes (MFC) and mild intra renal hemorrhage (MIRH). 


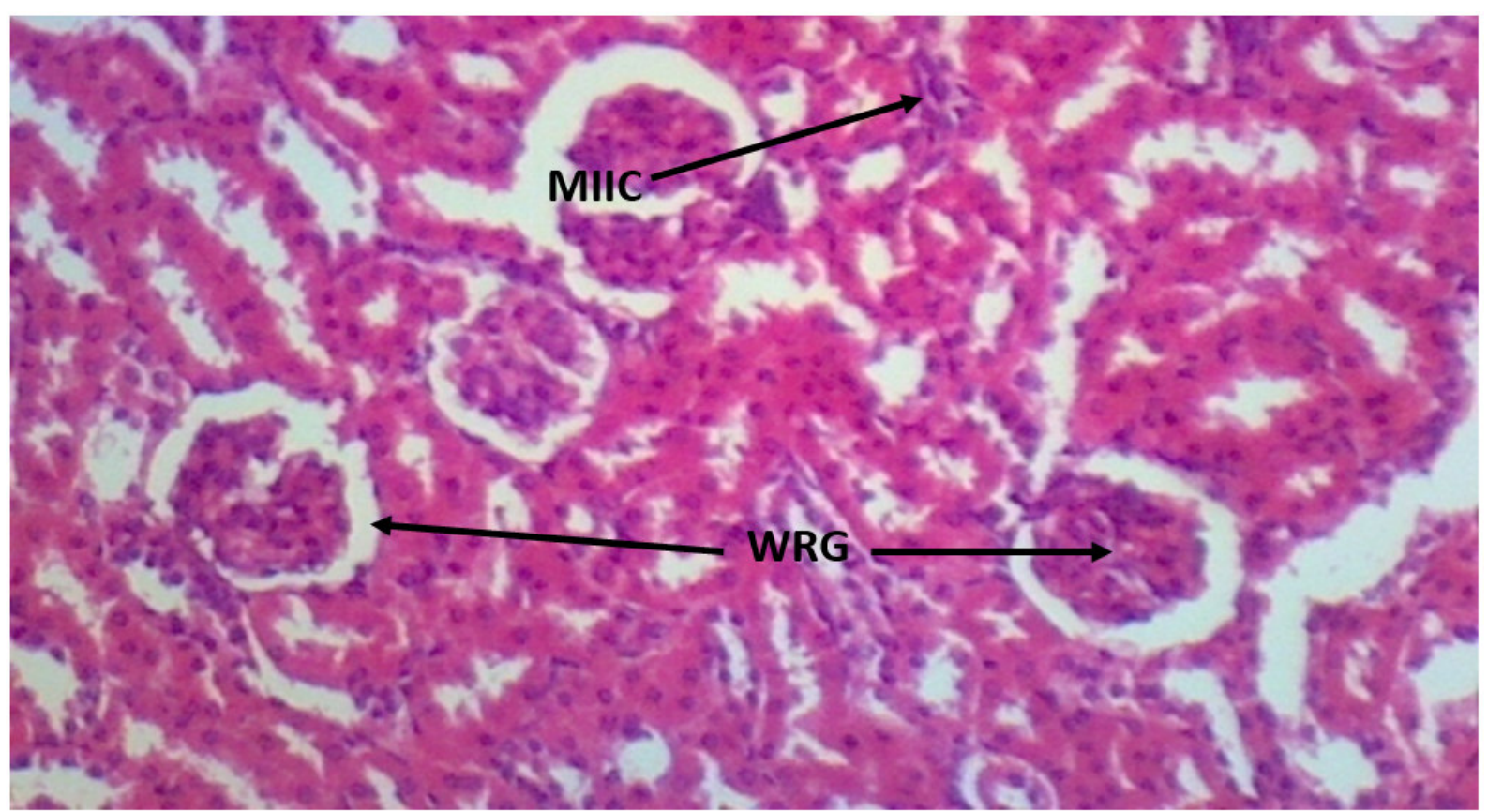

PLATE IV (GROUP D) (H\&E; X 400): Photomicrograph section of kidney induced with $150 \mathrm{mg} / \mathrm{kg}$ alloxan and treated with $250 \mathrm{mg} / \mathrm{kg}$ of cucumber pulp showing mild infiltration of inflammatory cell (MIIC) otherwise normal with well regenerated glomeruli (WRG).

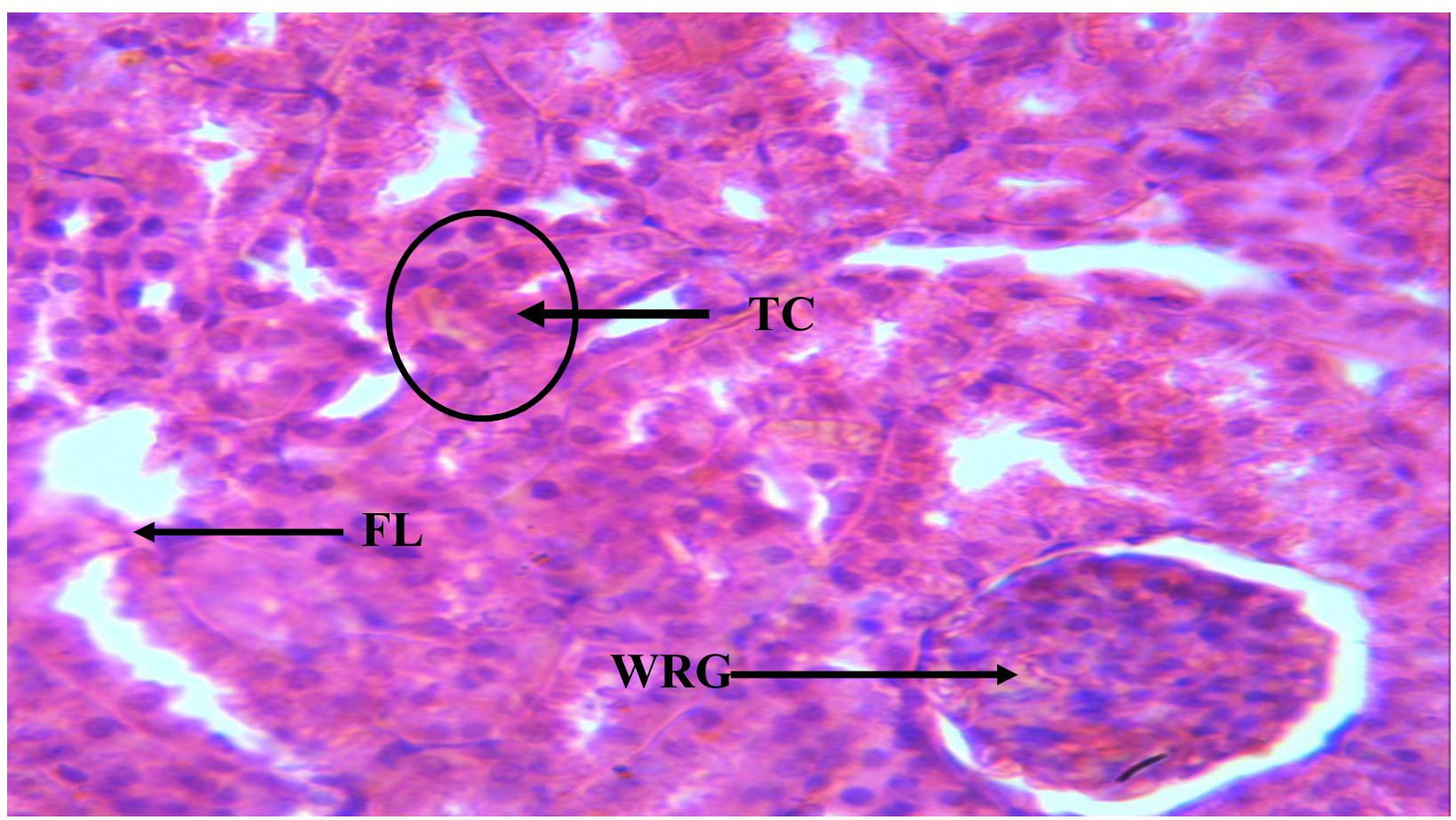

PLATE V (GROUP E) (H\&E; X 400): Administered intraperitoneally $150 \mathrm{mg} / \mathrm{kg}$ of Alloxan and treated with $500 \mathrm{mg} / \mathrm{kg}$ of cucumber pulp. Photomicrograph section of kidney shows focal loss (FL) otherwise normal with well regenerated glomeruli (WRG) and tubular cell (TC). 


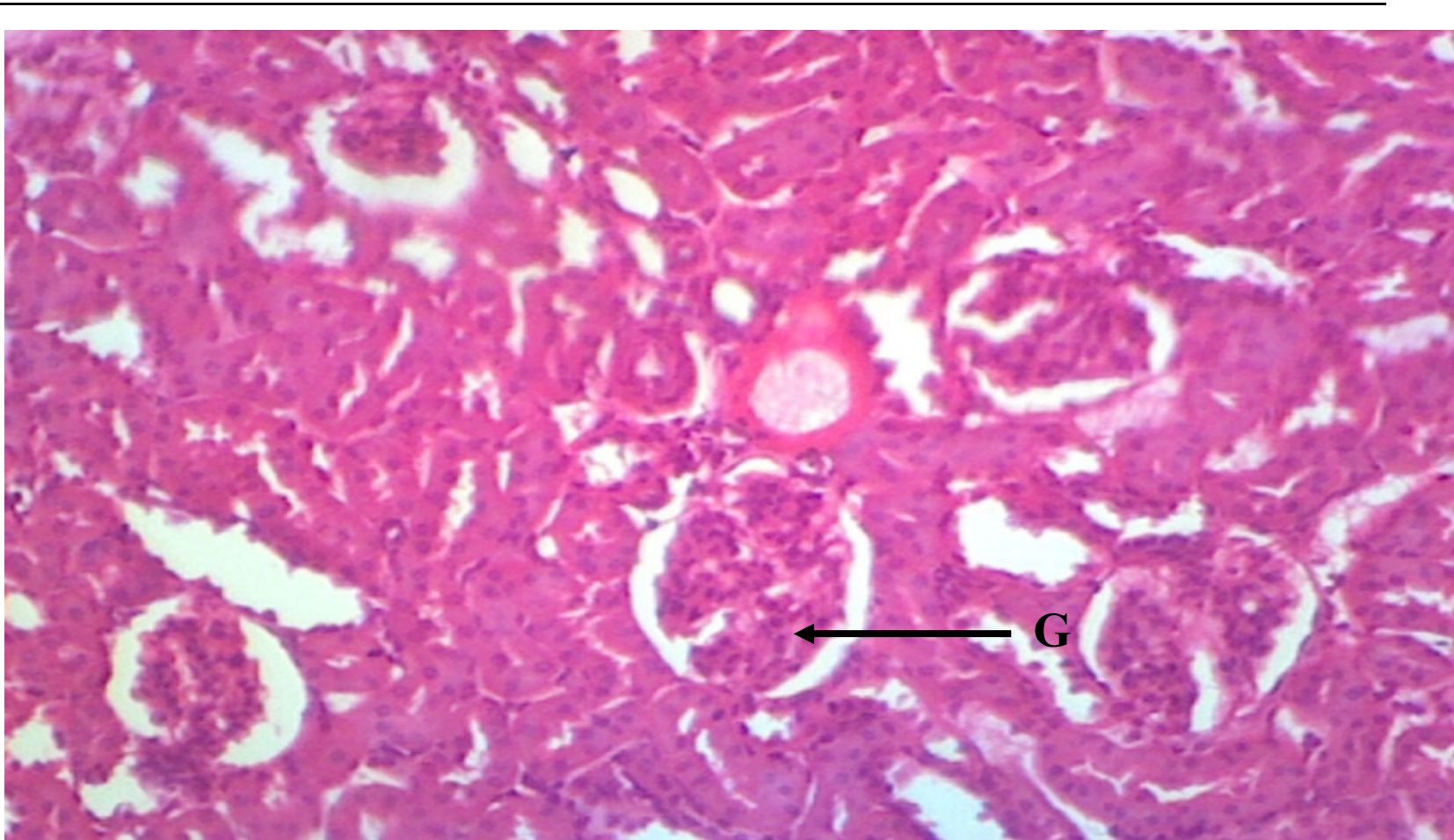

PLATE VI (GROUP F) (H\&E; X 400): Administered with 500mg/kg of Cucumber Pulp only. A photomicrograph section of the kidney shows well perfused renal tissue with glomeruli $(\mathrm{G})$ appearing normal.

\section{Discussion}

Plant derived remedies for various ailments have gained popularity especially in the rural areas of most developing countries. These plants contain phytochemicals that have been documented to be medicinal, promoting good health, aiding healing process, while at the same time causing cellular regeneration (Onyeka et al., 2013; Ofoego et al., 2017; Ofoego et al., 2018).

Findings from this study showed that a single intraperitoneal injection of $150 \mathrm{mg} / \mathrm{kg}$ of alloxan to male wistar rats weighing between 170-190g and left untreated, caused alterations in feeding habits which slightly improved as the experiment progressed, although the experimental animals got weaker as the experiment progressed with signs and symptoms characteristic of diabetes type 1. This alterations in feeding habits caused a significant decrease in the body weight $(\mathrm{P}<0.05)$ in the untreated diabetic group. This findings support the findings of Akbarzadeh et al., (2007), Muhammad et al., (2010), Ewenighi et al., (2015), and Ofoego et al., (2018) who all reported loss of weights in diabetic experimental animals. Diabetes is also usually accompanied with increased biochemical activities such as glycogenolysis, lipolysis, gluconeogenesis causing muscles wasting and loss of tissue protein (Ewenighi et al., 2015). However, in diabetic groups treated with ethanolic extract of Cucumis Sativus pulp, their feeding habits were improved, with resultant weight gains in a dose dependent manner although these gains were lower than that of control $(\mathrm{P}<0.05)$.

Kidneys maintain body homeostasis by optimizing the composition of body fluid through the removal of metabolic wastes such as urea and creatinine. Blood urea and creatinine levels, are routinely used as markers of renal functions, and are sensitive markers of renal damage (Olubunmi and Adeyemi, 2015). An increase in urea and creatinine concentration in all groups that received intraperitoneal administration of alloxan was observed in the current research when compared to control group indicating diabetic nephropathy, one of the most common complications due to diabetes (Donnelly et al., 2000; Lepedda et al., 2016). The increased levels of urea and creatinine observed could be as a result of impaired function of the kidney following damage caused by alloxan. Alloxan and its end product of reduction, dialuric acid, have been found to be involved in a redox cycle causing the production of large amounts of superoxide radicals. These radicals are converted to hydrogen peroxide by undergoing dismutation, causing alkylation of DNA. This leads to liberation of large toxic amounts of nitric oxide that inhibits aconitase activity causing DNA damage (Szkudelski, 2001), which could have led to the severe damage and necrosis of kidney tissue as observed in the micrograph of the untreated diabetic rat in this study. These findings agree with those of Hohenegger and Rudas, (1971), Abdulazeez, (2014), and Sharma et al., (2014). It has been documented, that serum levels of creatinine and urea increases when more than $50 \%$ of the renal mass is lost (Braun and Lefebvre, 2008). This is further confirmed by the kidney micrograph of untreated alloxan induced diabetic rats seen in this current research, which showed extensive necrosis.

However, it was evidenced that in the current research, administration of ethanolic extract of cucumis sativus 
pulp to alloxan induced diabetic rats caused a marked reduction in the serum levels of urea and creatinine in a dose dependent manner. Flavonoids, saponins, alkaloid, and steroids found in the ethanolic extract of cucumis sativus pulp used in this research has been documented to improve general diabetic conditions through various pathways such as improving glycolytic and glycogenic processes with simultaneous decline in glycogenolysis and gluconeogenesis (Andrade-Cetto et al., 2003). This could be behind the improvements in urea and creatinine levels observed after cucumis sativus administration to the diabetic rats, as well as improved feeding habits and renal histology seen in their respective micrographs. These improvements were however dose dependent. This pattern of activity could be as a result of these dietary flavonoids from cucumber synergizing with antioxidants for optimal cellular functions. They easily cross the cell membrane and cope with the intracellular ROS formation (Heidari et al., 2012). Studies have also isolated isovitexin and isoorientin, two C-glycosylflavones from cucumis sativus pulp. Both C-glycosylflavones have been reported to exhibit protective and antioxidant effects on animal tissues (Krauze-Baranowska and Cisowski, 2001).

The histopathological findings corroborated that Alloxan caused kidney damage with severe necrosis of tubular cell, coagulative necrosis of glomeruli, severe fatty change and tubular necrosis in untreated Alloxan group. This could without doubt, be as a result of the generation of reactive oxygen species (ROS) that caused damage to the kidney architecture by interfering with various biochemical activities thus impairing the function of the kidney (Donnelly et al., 2000; Lepedda et al., 2016). There was however a dose dependent restoration of the architecture of alloxan induced renal histology with treatment with graded doses of ethanolic extract of cucumis sativus pulp. $100 \mathrm{mg} / \mathrm{kg}$ of ethanolic extract of cucumis sativus pulp showed mild healing and restoration, $250 \mathrm{mg} / \mathrm{kg}$ of ethanolic extract of cucumis sativus pulp showed moderate healing of restoration of renal tissue architecture while treatment with $500 \mathrm{mg} / \mathrm{kg}$ of ethanolic extract of cucumis sativus pulp showed a superlative renal histology restoration, bring it near normal renal architecture. The presence of phytonutrients such as flavonoids and tannins found in cucumis sativus has the ability to cause regeneration of damaged tissues (Tapas et al., 2008).

\section{Conclusion}

This present study has shown that ethanolic extract of Cucumis sativus (Cucumber) pulp was able to ameliorate kidney damage resulting from alloxan induced diabetic nephropathy. This activity was however dose dependent.

\section{Acknowledgement}

We wish to express our profound gratitude to Mr. Emma Ezeokafor of the Physiology Department, Nnamdi Azikiwe University who helped in the practical aspect of this work, as well as Anokwulu Ifeanyi of the Department of Medicine for his help with the statistics.

\section{Refrences}

Abdulazeez, S.S. (2014). Effects of freeze-dried Fragaria x ananassa powder on alloxan-induced diabetic complications in Wistar rats. Journal of Taibah University Medical Sciences, 9(4), 268e 273.

Akbarzadeh, A., Norouzian, D., Mehrabi, M.R., Jamshidi, S.H., Farhangi, A., Allah, V.A., Mofidian S.M.A., Lame R.B. (2007). Induction of diabetes by streptozotocin in rats. Indian Journal of Clinical Biochemistry, 22(2), 60-64.

Andrade-Cetto, A., Wieldenfeld, H. (2003). Antihyperglycemic effect of Opuntia streptacantha Lem. $J$. Ethnopharmacol, 90.217.http://dx.doi.org/10 .1016/j.jep.2003, 09: 049.

Ankur, R., Shahjad, A. (2012). Alloxan induced diabetes: mechanisms and effects. Internat J Res Pharma Biomed Sci, 3, 819-821.

Braun, J.P., Lefebvre, H.P. (2008). Kidney function and damage. In: Kaneko, Harvey, Bruss (Eds), Clinical Biochemistry of Domestic Animals, 6 (London, Elsevier, 2008) 485 -528.

Das, J., Vasan, V., Sil, P.C. (2012). Taurine exerts hypoglycemic effect in alloxan-induced diabetic rats, improves insulin-mediated glucose transport signaling pathway in heart and ameliorates cardiac oxidative stress and apoptosis. Toxicol. Appl. Pharmacol., 258, 296-308.

Donnelly, R., Emslie-Smith, A.M., Gardner, I.D., Morris, A.D. (2000).Vascular complications of diabetes. Br Med $J ., 320,1062$.

Dunn, J. S., Sheehan, H. L., McLetchie, N.G.B. (1943). "Necrosis of Islets of Langerhans Produced Experimentally". Lancet. 241 (6242), 484-487.

Ebirien-Agana, S.B., Echeonwu, J.G., Ken-Ezihuo, S.U. (2016). The Effect of Cucumis Sativus (Cucumber) On Blood Glucose Concentration and Blood Pressure of Apparently Healthy Individuals in Port Harcourt. European Journal of Biomedical and Pharmaceutical sciences, 3(12), 108-114.

Evans, D., Griesbach, s. (1984). Regeneration.competence of cucumber handbook of plant cell culture volume1 ed. McMillian, new York,Us, pp 806 -815 .

Ewenighi, C., Dimkpa, U., Onyeanusi, J., Onoh, L., Onoh, G., Ezeugwu, U. (2015). Estimation of glucose level and body weight in Alloxan Induced Diabetic Rat treated with Aqueous extract of Garcinia Kola Seed. Ulutas 
Medical Journals, 1(2), 26-30.

Guyton, A.C., Hall, J.E. (2006). Textbook of Medical Physiology (11 ${ }^{\text {th }}$ edition). Philadelphia: W.B. Saunders.

Harborne, J.B. (1998). Phytochemical Methods - A Guide to Modern Techniques of plant analysis. London: Chapman and Hall.

Heidari, H., Kamalinejad, M., Eskandari, M. (2012). Hepatoprotective activity of Cucumis sativus against cumene hydroperoxide induced-oxidative stress. Res. Pharm. Sci., 7(5), S936-S939.

Hohenegger, M., Rudas, B. (1971). Kidney Function in Experimental Diabetic Ketosis. Diabetologia, 7, 334 338.

Huang, S., Li, R., Zhang, Z., Li, L., Gu, X., Fan, W., Lucas, W.J., Wang, X., Xie, B., Ni, P., Ren, Y., Zhu, H., Li, J., Lin, K., Jin, W., Fei, Z., Li, G., Staub, J., Kilian, A., van der Vossen, E.A., Wu, Y., Guo, J., He, J., Jia, Z., Ren, Y., Tian, G., Lu, Y., Ruan, J., Qian, W., Wang, M., Huang, Q., Li, B., Xuan, Z., Cao, J., Asan, Wu Z., Zhang, J, Cai, Q., Bai, Y., Zhao, B., Han, Y., Li, Y., Li, X., Wang, S, , Shi, Q., Liu, S., Cho, W.K., Kim, J.Y., Xu, Y., Heller-Uszynska, K., Miao, H., Cheng, Z., Zhang, S., Wu, J., Yang, Y., Kang, H., Li, M., Liang, H., Ren, X., Shi, Z., Wen, M., Jian, M., Yang, H., Zhang, G., Yang, Z., Chen, R., Liu, S., Li, J., Ma, L., Liu, H., Zhou, Y., Zhao, J., Fang, X., Li, G., Fang, L., Li, Y., Liu, D., Zheng, H., Zhang, Y., Qin, N., Li, Z., Yang, G., Yang, S., Bolund, L., Kristiansen, K., Zheng, H., Li, S., Zhang, X., Yang, H., Wang, J., Sun, R., Zhang, B., Jiang, S., Wang, J., Du, Y., Li, S. (2009). The genome of the cucumber, Cucumis sativus L. Nat Genet., 41(12), 1275-81.

Jony, M., Priyanka, D., Sourav, D. (2013). Pharmacological activity of Cucumissativs L.-A complete overview. Asian Journal of Pharmaceutical Research and Development, 1(1), 2320-4850.

Khalili, H., Bairami, S., Kargar, M. (2013). Antibiotics induced acute kidney injury: incidence, risk factors, onset time and outcome. Acta Med Iran, 51(12), 871-8.

Krauze-Baranowska, M.A., Wojciech, C. (2001). Flavonoids from some species of the genus Cucumis. Biochemical Systematics and Ecology, 29(3), 321-324.

Kumar, D., Kumar, S., Singh, J., Narender, R., Vashistha, B., Singh, N. (2010). Free Radical Scavenging and Analgesic Activities of Cucumis sativus L. Fruit Extract. J Young Pharm., 2(4), 365-8.

Lenzen, S., Munday, R. (1991). Thiol-group reactivity, hydrophilicity and stability of alloxan, its reduction products and its N-methyl derivatives and a comparison with ninhydrin. Biochem Pharmacol., 12, 42(7):1385-91.

Lenzen, S. (2008). "The Mechanisms of Alloxan- and Streptozotocin-induced Diabetes". Diabetologia, 51(2), 216-226.

Lepedda, A.J., De Muro, P., Capobianco, G., Formato, M. (2016). Significance of urinary glycosaminoglycans/proteoglycans in the evaluation of type 1 and type 2 diabetes complications. J Diabetes Complications. 2016. doi: 10.1016/j.jdiacomp.2016.10.013.

Marsh, W.H., Fingerhut, B., Miller, H. (1965). Automated and manual direct methods for the determination of blood urea. Clinical chemistry, 11, 624-627.

Mohamed, M., Mediha, S., Hamadi, F., El-Mouldi, G., Nabil, K.G., Tahia, B., et al. (2010). Flax and Pumpkin seeds mixture ameliorates diabetic nephropathy in rats. Food Chem Toxicol., 48, 2407-2412.

Muhammad, Z., Syed, N.N. (2010). Effects of STZ-Induced Diabetes on the Relative Weights of Kidney, Liver and Pancreas in Albino Rats: A Comparative Study. Int. J. Morphol., 28(1),135-142.

Munday, R. (1988). Dialuric acid autoxidation. Effect of transition metals on the reaction rate and on generation of 'active oxygen' species. Biochem. Pharmacol., 37, 409-413.

Olubunmi, G.A., Adeyemi, S.A. (2015). Effect of Allium Cepa Supplemented Diets on Plasma Glucose, Electrolytes and Renal Histology of Streptozotocin-Induced Diabetic Rats. IOSR Journal of Pharmacy and Biological Sciences (IOSR-JPBS), 10(4), 25-32.

Onyeka, C.A., Nwakanma, A.A., Bakare, A.A., Okoko, I.I., Ofoego, U.C., Wali, C.C., Abengowe, F.C. (2013). Hypoglycemic, Antioxidant and Hepatoprotective Activities of Ethanolic Root Bark Extract of Chrysophyllum albidum in Alloxan-Induced Diabetic Rats. Bangladesh Journal of Medical Science, 12(3), 298-304.

Owen, J.A., Iggo, B., Scandrett, F.J., Stewart, C.P. (1954). The determination of creatinine in plasma or serum, and in urine; a critical examination. The Biochemical Journal, 58(3), 426-437.

Rubina, N. (2017). Acute kidney injury from different poisonous substances. World J Nephrol., 6(3), $162-167$.

Sharma, B., Mohd, S.S., Gurudayal, R., Ranjeet, K.Y., Arti, K., Gaurav, S., and Nakuleshwar, D.J. (2014). Rejuvenating of Kidney Tissues on Alloxan Induced Diabetic Mice under the Effect of Momordica charantia. Advances in Pharmaceutics, 2014, 1-9.

Szkudelski, T. (2001). The mechanism of alloxan and streptozotocin action in B cells of the rat pancreas. Physiol Res., 50(6), 537-46.

Tapas, A., Sakarka, D., Kakde, R. (2008). A review of flavonoids as nutraceuticals. Trop J Pharm Res., 7, 10891099. 
Tiwari, P., Kumar, B., Kaur, M., Kaur, G. and Kaur, H. (2011). Phytochemical screening and Extraction: A Review. Internationale Pharmaceutica Sciencia, 1(1), 98-106.

Trease, G.E., and Evans, W.C. (2002). Trease and evanspharmacognosy. 15th ed. London: WB Saunders :419473.

Ofoego, U.C., Nwakanma, A., Ekwujuru, E.U., Nweke, E.O. (2018). Effect of Ethanolic Leaf Extract of Sida Corymbosa (Wire Weed) on Alloxan Induced Pancreatic Damage in Adult Male Wistar Rats. Journal of Natural Sciences Research, 8(10), 54-66.

Ofoego, U.C., Ekwujuru, E.U., Nwakanma, A., Mbagwu, I.S., Nweke, E.O., Anibeze, C.I.P. (2018). Protective and Ameliorating Effects of Methanolic Seed Extract of Mucuna Pruriens on Paraquat Induced Testicular Damage. Advances in Life Science and Technology, 53, 8-16.

Ofoego, U.C., Nwachukwu, O., Ekwujuru, E.U., Mbagwu, I.S., Nwakanma, A., Nweke, E.O., Ofoego, A.N. (2017). Ethanolic Seed Extract of Cucurbita Pepo (Pumpkin) Protects the Testis from Azadirachta Indica (Neem) Induced Damage. Journal of Natural Sciences Research, 7(24), 120-131.

Walter, N.H. (1905).The preparation of murexide from alloxantin and alloxan. Journal of the Chemical Society, Transactions, 87, 1791-1795.

Yui, T., Yasushi, K., Tetsuro, M., and Kiyokazu, O. (2017). Acute alloxan renal toxicity in the rat initially causes degeneration of thick ascending limbs of Henle. J Toxicol Pathol, 30(1), 7-13.

Zhang, H., Gao, G., Brunk, U.T. (1992). Extracellular reduction of alloxan results in oxygen radical- -mediated attack on plasma and lysosomal membranes. APMIS, 100, 317-325. 